\title{
On the Reduced Game Property and its Converse
}

\section{A Correction}

By B. Peleg

Remark 4.7 in Peleg (1986) is incorrect. If a single-valued solution satisfies COV and RGP, then it satisfies PO. However, the foregoing claim is not true for set-valued solutions. Indeed, the following example shows that $\mathrm{PO}$ is independent of $\mathrm{COV}$ and RGP.

Example 1: Let $(N, v)$ be a game. Define

$$
\sigma(N, v)=\left\{x \in X^{*}(N, v) \mid s_{i j}(x)=s_{j i}(x) \text { for all } i \neq j\right\}
$$

Then, as the reader can easily verify, $\sigma$ satisfies NE, ETP, COV, RGP, and CRGP. Also, $\sigma$ violates PO (see the notations of Peleg 1986).

Remark 2: We conclude from Example 1 and Peleg (1986) that the following six independent axioms characterize the prekernel: NE, PO, ETP, COV, RGP, and CRGP.

I am grateful to Mr. Benny Moldovanu for pointing out the foregoing mistake.

\section{Reference}

Peleg B (1986) On the reduced game property and its converse. International Journal of Game Theory $15: 187-200$ 